\title{
ANALISIS PERHITUNGAN DENGAN METODE PROFILE MATCHING UNTUK MEMILIH PENERIMA BEASISWA BIDIKMISI
}

\author{
Kelik Sussolaikah ${ }^{1}$, Nabila Payapo ${ }^{2}$, Ramlan $^{3}$, Khoirul Islam $^{4}$, Kusrini $^{5}$ \\ Magister Teknik Informatika \\ Universitas AMIKOM Yogyakarta \\ E-mail: 11vielisabeth27@gmail.com, 2payapo_nabila@yahoo.co.id, \\ ${ }^{3}$ ramlantux@gmail.com, ${ }^{4}$ khoirulislam@gmail.com, ${ }^{5}$ kusrini@amikom.ac.id
}

\begin{abstract}
ABSTRAK
Penetilian ini bersifat eksperimen dengan melakukan analisis perhitungan dengan metode Profile Matching untuk memilih penerima beasiswa Bidikmisi. Lima macam persyaratan dalam aturan pemberian beasiswa Bidikmisi diimplementasikan menjadi lima macam kriteria pada proses perhitungan manual untuk menghasilkan suatu keluaran yang berisi informasi perankingan nilai prioritas secara descending para calon penerima beasiswa Bidikmisi.
\end{abstract}

Kata Kunci-Aplikasi, beasiswa, kriteria, nilai, descending 


\begin{abstract}
This assessment is experimental by analyzing calculations using the Profile Matching method to select Bidikmisi scholarship recipients. The five types of requirements in the Bidikmisi scholarship rules are implemented into five types of criteria in the manual calculation process to produce an output containing descending priority value ranking information for Bidikmisi scholarship recipients.
\end{abstract}

Kata Kunci-Aplication scholarship, criteria, descending value 


\section{PENDAHULUAN}

Setiap warga Negara Republik Indonesia berhak mendapatkan pengajaran. Hak setiap warga Negara tersebut telah dicantumkan dalam Pasal 31 (1) Undang-Undang Dasar 1945. Berdasarkan pasal tersebut, maka Pemerintah dan Pemerintah Daerah wajib memberikan layanan dan kemudahan, serta menjamin terselenggaranya pendidikan yang bermutu bagi setiap warga negara tanpa diskriminasi, dan masyarakat berkewajiban memberikan dukungan sumber daya dalam penyelenggaraan pendidikan. Untuk menyelenggarakan pendidikan yang bermutu diperlukan biaya yang cukup besar. Oleh karena itu setiap peserta didik pada satuan pendidikan berhak mendapatkan bantuan biaya pendidikan bagi mereka yang memiliki potensi akademik baik dan tidak mampu secara ekonomi serta berhak mendapatkan beasiswa bagi mereka yang berprestasi [1].

Peningkatan pemerataan akses jenjang perguruan tinggi sampai saat ini masih merupakan masalah di negara kita karena Angka Partisipasi Kasar (APK) baru mencapai $27.63 \%$ yang melanjutkan ke perguruan tinggi masih rendah dibandingkan dengan negara lain [1]. Dengan demikian masih cukup banyak lulusan jenjang pendidikan menengah yang tidak dapat melanjutkan ke perguruan tinggi termasuk mereka yang berpotensi akademik baik dari keluarga tidak mampu secara ekonomi.

Pemerintah mulai tahun 2010 meluncurkan Program Bantuan Biaya Pendidikan Bidikmisi yaitu bantuan biaya pendidikan bagi calon mahasiswa tidak mampu secara ekonomi dan memiliki potensi akademik baik untuk menempuh pendidikan di perguruan tinggi pada program studi unggulan sampai lulus tepat waktu [1].

Beberapa jurnal penelitian yang telah membahas metode yang dipakai di dalam sistem pengambilan keputusan dengan metode Profile Matching ataupun membahas bantuan beasiswa adalah:

Metode Profile Matching telah diterapkan oleh T.M Syahru Ichsan pada tahun 2015 untuk membangun suatu sistem pendukung keputusan untuk pemilihan penerima beasiswa mahasiswa kurang mampu. Penelitian ini menarik perhatian tim peneliti untuk mengetahui langkah-langkah penyelesaian permasalahan dengan metode Profile Matching.

Sistem Pendukung Keputusan untuk memilih mahasiswa berprestasi telah diteliti pada tahun 2015. Penelitian oleh Tri Ferga Presetyo dan rekan ini menarik sebab kriteria 
yang digunakan pada sistem ini mengacu pada pedoman pemilihan mahasiswa berprestasi yang diterbitkan oleh DIKTI tahun 2015, yaitu meliputi nilai IPK, karya tulis ilmiah, prestasi/kemampuan yang diunggulkan, dan Bahasa Inggris.

Tahun 2015 Kusnadi dan rekan menerapkan metode Profile Matching untuk membangun suatu sistem Pendukung Keputusan ini dapat membantu direktur utama dalam menentukan karyawan mana yang layak untuk dipromosikan menduduki suatu jabatan.

Ria Astriratma dan rekan kembali melakukan penelitian pada tahun 2017 dengan metode Profile Matching untuk proses penilaian para kandidat Pejabat Struktural di Kota Tarakan dapat dilakukan oleh sistem, sehingga membantu meminimalisir terjadinya keputusan yang subjektif.

Dari penelitian-penelitian yang telah dilakukan seperti disebutkan pada alinea di atas maka penelitian kali ini ditujukan untuk menentukan nilai prioritas para calon penerima beasiswa Bidikmisi, yang mana hasil penelitian ini adalah berupa suatu rancangan dari sistem pendukung keputusan yang menerapkan metode Profile Matching. Selain dari sumber beberapa jurnal penelitian, tim peneliti juga mempelajari hal-hal yang terkait dengan pemberian beasiswa Bidikmisi, yaitu terutama untuk mengetahui macammacam kriteria/persyaratan yang ditetapkan oleh pemerintah untuk memberikan beasiswa Bidikmisi kepada para lulusan Sekolah Menengah Atas dan sederajat agar dapat melanjutkan studi ke jenjang Strata-1.

\section{DASAR TEORI}

\subsection{Pengambilan Keputusan}

Djahir dan Dewi (2014:26) mengatakan bahwa "Keputusan merupakan rangkaian tindakan yang perlu diikuti dalam memecahkan masalah untuk menghindari atau mengurangi dampak negatif atau untuk memanfaatkan kesempatan". Menurut Nofriansyah (2014:1) mengemukakan bahwa "Sistem pendukung keputusan (SPK) biasanya dibangun untuk mendukung solusi atas suatu masalah atau untuk suatu peluang".

\subsection{Profile Matching}

Profile matching merupakan suatu proses yang sangat penting dalam manajemen SDM dimana terlebih dahulu ditentukan kompetensi (kemampuan) yang diperlukan oleh suatu jabatan. Kompetensi atau kemampuan tersebut haruslah dapat dipenuhi oleh 
pemegang atau calon pemegang jabatan. Dalam proses profile matching secara garis besar merupakan proses membandingkan antara kompetensi individu kedalam kompetensi jabatan sehingga dapat diketahui perbedaan kompetensinya (disebut juga Gap), semakin kecil gap yang dihasilkan maka bobot nilainya semakin besar yang berarti memiliki peluang lebih besar untuk pegawai yang menempati posisi tersebut. (Sianturi, 2015:45).

\section{METODE PENELITIAN}

\subsection{Jenis, Sifat, dan Pendekatan Penelitian}

Jenis penelitian yang dilakukan adalah eksperimen, yaitu tim peneliti mengumpulkan bahan-bahan penelitian berupa e-book panduan yang membahas Bidikmisi dan mengumpulkan jurnal-jurnal penelitian yang dapat mendukung pemahaman mengenai metode Profile Matching. Dari e-book Bidikmisi dan jurnal-jurnal penelitian terdahulu yang membahas metode Profile Matching kemudian dipakai oleh tim peneliti untuk melakukan eksperimen pencarian solusi yaitu dengan melakukan perhitungan manual (di atas kertas) untuk memilih penerima beasiswa Bidikmisi.

Sifat penelitian adalah deskriptif, yaitu mendeskripsikan kegiatan penelitian dari tahap analisis perhitungan sampai menghasilkan membuat suatu keluaran berupa informasi perankingan nilai prioritas masing-masing calon penerima beasiswa Bidikmisi.

Pendekatan penelitian ini adalah bersifat kualitatif, yaitu memahami cara kerja algoritma Profile Matching yang kemudian langkah-langkah pada algoritma itu dipakai pada analisis perhitungan manual untuk dapat menghasilkan keluaran berupa perankingan nilai prioritas para calon penerima beasiswa Bidikmisi.

\subsection{Metode Pengumpulan Data}

Pengumpulan data pada penelitian ini dengan mencari e-book mengenai beasiswa Bidikmisi dan memahami aturan maupun kriteria-kriteria dalam penerimaan beasiswa ini. Kriteria-kriteria dalam penerimaan beasiswa Bidikmisi pada Tabel 1. 
Tabel 1. Kriteria Bidikmisi [1] dan Bobot Kriteria [2] yang Ditetapkan oleh Tim Peneliti

\begin{tabular}{|l|l|c|}
\hline Nama & \multicolumn{1}{|c|}{$\begin{array}{l}\text { Keterangan Kriteria } \\
\text { Bidikmisi }\end{array}$} & Bobot \\
\hline K1 & $\begin{array}{l}\text { Usia pendaftar maksimal 21 } \\
\text { tahun untuk calon } \\
\text { mahasiswa S-1 }\end{array}$ & $10 \%$ \\
\hline K2 & $\begin{array}{l}\text { Penerima BSM*) atau } \\
\text { pemegang KIP/KIS*) }\end{array}$ & $30 \%$ \\
\hline K3 & $\begin{array}{l}\text { Penghasilan kotor gabungan } \\
\text { ortu/wali Rp 3.000.000,00 } \\
\text { atau maksimal Rp } \\
750.000,00 \text { tiap bulan }\end{array}$ \\
\hline K4 & $\begin{array}{l}\text { Pendidikan maksimal } \\
\text { orangtua/wali maksimal S-1 } \\
\text { atau D-4 }\end{array}$ & $15 \%$ \\
\hline K5 & Memiliki potensi akademik & $15 \%$ \\
\hline
\end{tabular}

*) $\mathrm{BSM}=$ Bantuan Siswa Miskin.

*) KIP = Kartu Indonesia Pintar.

*) KIS = Kartu Indonesia Sejahtera.

Nilai-nilai pada kolom Bobot merupakan nilai-nilai yang ditetapkan oleh tim peneliti sebab e-book Bidikmisi tidak menuliskan nilai-nilai bobot itu.

Kriteria K3 dan kriteria K4 memiliki beberapa pilihan dan nilai seperti yang ditulis pada Tabel 2 dan Tabel 3.

Tabel 2. Nilai Kriteria Penghasilan Orangtua/Wali

\begin{tabular}{|l|l|r|}
\hline Kode & \multicolumn{1}{|c|}{$\begin{array}{l}\text { Pilihan Kriteria Penghasilan } \\
{[1]}\end{array}$} & $\begin{array}{c}\text { Nil } \\
\text { ai }\end{array}$ \\
\hline Inc1 & $\begin{array}{l}\text { Kurang dari atau sama } \\
\text { dengan Rp 750.000,00 }\end{array}$ & 8 \\
\hline Inc2 & $\begin{array}{l}\text { Antara Rp 750.000,00 } \\
\text { sampai Rp 1.500.000,00 }\end{array}$ & 6 \\
\hline Inc3 & $\begin{array}{l}\text { Antara Rp 1.500.000,00 } \\
\text { sampai Rp 2.250.000,00 }\end{array}$ & 4 \\
\hline Inc4 & $\begin{array}{l}\text { Antara Rp 2.250.000,00 } \\
\text { sampai Rp 3.000.000,00 }\end{array}$ & 2 \\
\hline
\end{tabular}

Nilai-nilai pada kolom Nilai merupakan nilai-nilai yang ditetapkan oleh tim peneliti sebab e-book Bidikmisi tidak menuliskan nilai-nilai itu. 


\section{Tabel 3. Nilai Kriteria Pendidikan Orangtua/Wali}

\begin{tabular}{|l|l|r|}
\hline Kode & \multicolumn{1}{|c|}{$\begin{array}{c}\text { Pilihan Kriteria } \\
\text { Pendidikan [1] }\end{array}$} & $\begin{array}{c}\text { Nil } \\
\text { ai }\end{array}$ \\
\hline Sk11 & Tidak sekolah & 10 \\
\hline Sk12 & Sekolah Dasar & 8 \\
\hline Sk13 & $\begin{array}{l}\text { Sekolah Menengah } \\
\text { Pertama }\end{array}$ & 6 \\
\hline Sk14 & Sekolah Menengah Atas & 4 \\
\hline Sk15 & Strata-1 atau Diploma-4 & 2 \\
\hline
\end{tabular}

Nilai-nilai pada kolom Nilai merupakan nilai-nilai yang ditetapkan oleh tim peneliti sebab e-book Bidikmisi tidak menuliskan nilai-nilai itu.

Untuk keperluan penangkapan data dari para calon penerima beasiswa Bidikmisi tim peneliti membuat suatu form pada Gambar 1 yang harus diisi oleh para calon penerima beasiswa Bidikmisi. Data isian pada form ini disusun oleh tim peneliti berdasarkan data yang telah ditulis pada Tabel 1 sampai Tabel 3. Data isian pada form ini diperlukan untuk keperluan proses perhitungan dalam rangka pencarian solusi dengan metode Profile Matching yang dibahas pada sub Hasil dan Pembahasan.

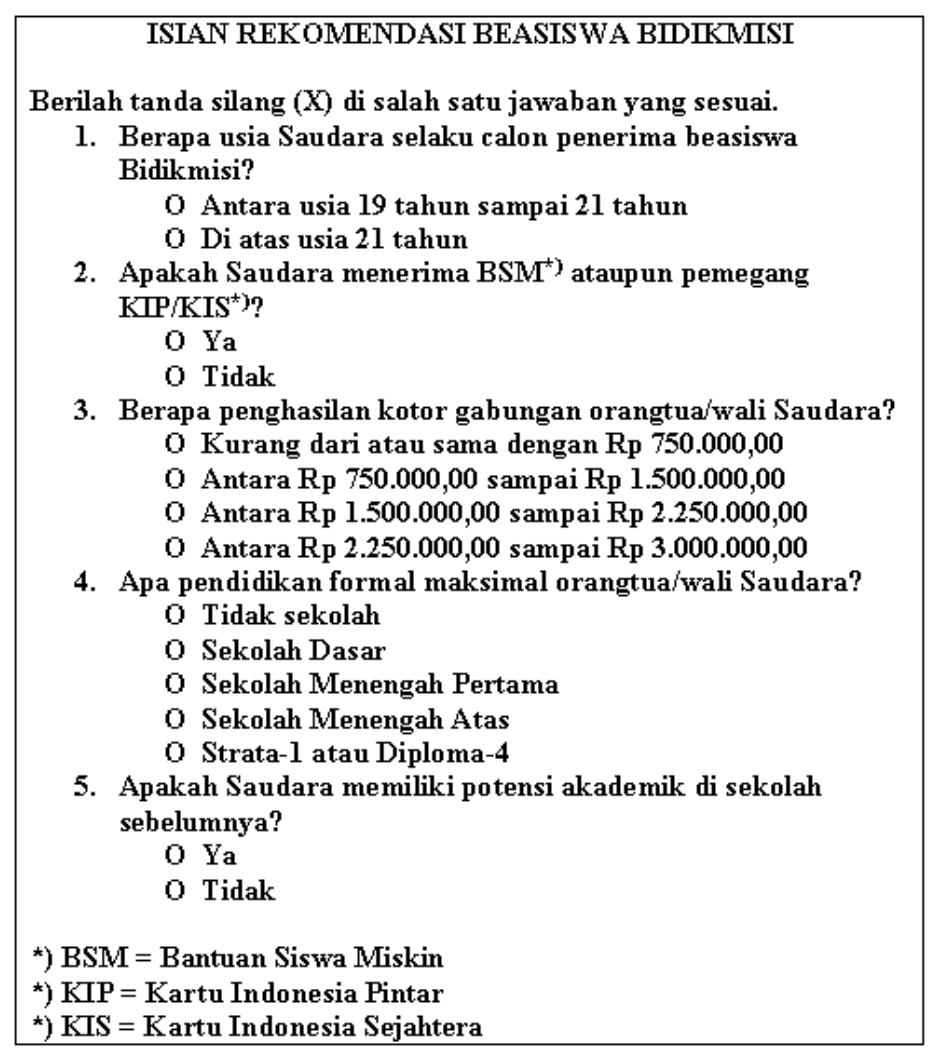

Gambar 1. Form Rekomendasi Bidikmisi 


\subsection{Metode Analisis Data}

Analisis data yang dilakukan oleh peneliti meliputi:

a. Mengklasifikasi Data

Klasifilasi data dibuat sesuai kriteria-kriteria yang akan diuji oleh metode Profile Matching dalam rancangan sistem pendukung keputusan sesuai keperluan pemberian beasiswa Bidikmisi. Macam-macam kriteria ini telah ditulis pada Tabel 1. Macam-macam kriteria ini kemudian menjadi pertanyaan-pertanyaan yang ditulis pada form rekomendasi Bidikmisi seperti yang telah ditunjukkan pada Gambar 1.

b. Menganalisis Data

Analisis data dilakukan dalam proses perhitungan sesuai metode sistem pendukung keputusan yang dimaksudkan untuk mencari kesimpulan/solusi akhir, yaitu berupa ranking prioritas calon penerima dalam menerima dana beasiswa Bidikmisi.

c. Memaknai Data

Memaknai data bertujuan untuk menghindari kesalahan dalam proses perhitungan, sebab setiap kriteria memiliki nilai bobot yang telah ditentukan di Tabel 1, kemudian kriteria K3 dan kriteria K4 masih memiliki nilai-nilai seperti yang tertulis pada Tabel 2 dan Tabel 3.

d. Menarik Kesimpulan

Penarikan kesimpulan dilakukan atas hasil akhir (solusi) dari metode sistem pendukung keputusan yang dipilih.

\section{HASIL DAN PEMBAHASAN}

Dimisalkan diperoleh data hasil jawaban pada Form Rekomendasi Bidikmisi (Gambar 1) dari beberapa calon penerima beasiswa seperti yang ditulis pada Tabel 4.

Tabel 4. Data Jawaban Form Rekomendasi Bidikmisi Calon Penerima Beasiswa

\begin{tabular}{|l|r|c|c|c|c|}
\hline \multirow{2}{*}{ Nama } & \multicolumn{5}{|c|}{ Kriteria Dari Bidikmisi } \\
\cline { 2 - 6 } & Umur & $\begin{array}{c}\text { BSM/ } \\
\text { KIP/ } \\
\text { KIS }\end{array}$ & $\begin{array}{c}\text { Penghasi } \\
\text { lan }\end{array}$ & $\begin{array}{c}\text { Pendidik } \\
\text { an }\end{array}$ & $\begin{array}{c}\text { Potensi } \\
\text { Akadem } \\
\text { k }\end{array}$ \\
\hline Nabila & 21 & Ya & Inc1 & Sk11 & Ya \\
\hline Kelik & 20 & Tidak & Inc2 & Sk12 & Ya \\
\hline Ramlan & 19 & Tidak & Inc3 & Sk13 & Ya \\
\hline Khois & 18 & Tidak & Inc4 & Sk14 & Tidak \\
\hline Zaenal D & 20 & Ya & Inc4 & Sk15 & Tidak \\
\hline Zaenal M & 19 & Ya & Inc3 & Sk12 & Tidak \\
\hline
\end{tabular}


Pencarian solusi melalui penyelesaian dengan metode Profile Matching dijelaskan pada sub 3.1 di bawah ini.

\subsection{Pencarian Solusi dengan Metode Profile Matching}

Data acuan mengenai bobot nilai gap sesuai aturan metode Profile Matching ditulis pada Tabel 4.

Tabel 5. Bobot Nilai Gap [3]

\begin{tabular}{|l|l|l|}
\hline $\begin{array}{c}\text { Selisih } \\
\text { Gap }\end{array}$ & $\begin{array}{c}\text { Bobot } \\
\text { Nilai }\end{array}$ & \multicolumn{1}{|c|}{ Keterangan } \\
\hline 0 & 5,0 & $\begin{array}{l}\text { Kriteria sesuai dengan } \\
\text { yang dibutuhkan }\end{array}$ \\
\hline 1 & 4,5 & $\begin{array}{l}\text { Kriteria kelebihan 1 } \\
\text { tingkat/level }\end{array}$ \\
\hline-1 & 4,0 & $\begin{array}{l}\text { Kriteria kurang 1 } \\
\text { tingkat/level }\end{array}$ \\
\hline 2 & 3,5 & $\begin{array}{l}\text { Kriteria kelebihan 2 } \\
\text { tingkat/level }\end{array}$ \\
\hline-2 & 3,0 & $\begin{array}{l}\text { Kriteria kurang 2 } \\
\text { tingkat/level }\end{array}$ \\
\hline 3 & 2,5 & $\begin{array}{l}\text { Kriteria kelebihan 3 } \\
\text { tingkat/level }\end{array}$ \\
\hline-3 & 2,0 & $\begin{array}{l}\text { Kriteria kurang 3 } \\
\text { tingkat/level }\end{array}$ \\
\hline 4 & 1,5 & $\begin{array}{l}\text { Kriteria kelebihan 4 } \\
\text { tingkat/level }\end{array}$ \\
\hline-4 & 1,0 & $\begin{array}{l}\text { Kriteria kurang 4 } \\
\text { tingkat/level }\end{array}$ \\
\hline
\end{tabular}

Dengan data pada Tabel 4 dapat dilakukan tahap-tahap pencarian solusi dengan metode Profile Matching yang meliputi langkah-langkah di bawah ini:

a. Penilaian Jawaban pada Form Rekomendasi

Data pada Tabel 4 dapat diberi nilai seperti yang tertulis pada Tabel 6 .

Tabel 6. Penilaian Form Rekomendasi

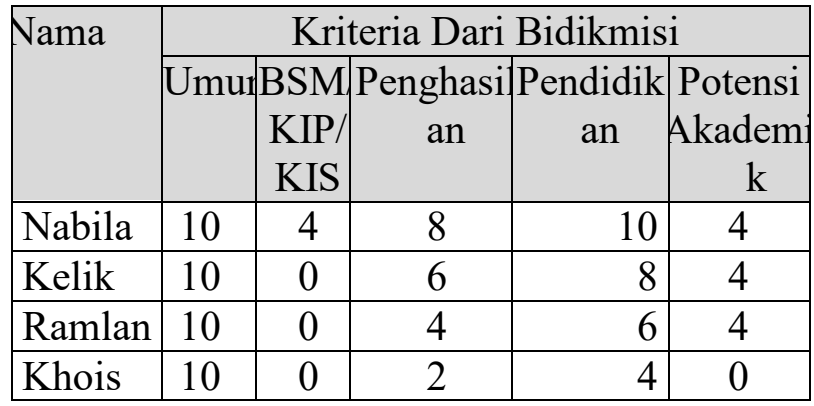




\begin{tabular}{|l|l|l|l|r|c|}
\hline $\begin{array}{l}\text { Zaenal } \\
\text { D }\end{array}$ & 10 & 4 & 2 & 2 & 0 \\
\hline $\begin{array}{l}\text { Zaenal } \\
\text { M }\end{array}$ & 10 & 4 & 4 & 8 & 0 \\
\hline
\end{tabular}

Nilai-nilai khusus untuk kriteria Penghasilan dan kriteria Pendidikan diberikan berdasarkan ketentuan nilai pada Tabel 2 dan Tabel 3. sedangkan nilai-nilai untuk selain kriteria Penghasilan dan kriteria Pendidikan diberikan oleh tim peneliti dengan memperhatikan kolom Selisih Gap pada Tabel 5, agar di langkah (b) dapat menghasilkan nilai-nilai yang masih masuk dalam batasan Bobot Nilai yang tertulis pada Tabel 5 .

b. Menghitung Gap [4]

Data pada Tabel 6 kemudian dikurangkan dengan nilai-nilai yang ditetapkan tim peneliti pada baris Pengurang untuk mendapatkan hasil selisih di setiap kriteria seperti yang tertulis di Tabel 7.

Tabel 7. Selisih Gap Di Setiap Kriteria

\begin{tabular}{|c|c|c|c|c|c|}
\hline \multirow[t]{3}{*}{ Nama } & \multicolumn{5}{|c|}{ Nilai Pengurang untuk Tiap-tiap Kriteria } \\
\hline & \multicolumn{4}{|c|}{ UmurBSM,Penghasila Pendidik } & \multirow{2}{*}{$\begin{array}{c}\text { Potensi } \\
\text { Akademik }\end{array}$} \\
\hline & & $\begin{array}{l}\text { KIP/ } \\
\text { KIS }\end{array}$ & $\mathrm{n}$ & an & \\
\hline Nabila & 10 & 4 & 8 & 10 & 4 \\
\hline Kelik & 10 & 0 & 6 & 8 & 4 \\
\hline Ramlan & 10 & 0 & 4 & 6 & 4 \\
\hline Khois & 10 & 0 & 2 & 4 & 0 \\
\hline Zaenal D & 10 & 4 & 2 & 2 & 0 \\
\hline Zaenal M & 10 & 4 & 4 & 8 & 0 \\
\hline Pengurang & 10 & 4 & 5 & 6 & 4 \\
\hline Nabila & 0 & 0 & 3 & 4 & 0 \\
\hline Kelik & 0 & -4 & 1 & 2 & 0 \\
\hline Ramlan & 0 & -4 & -1 & 0 & 0 \\
\hline Khois & 0 & -4 & -3 & -2 & -4 \\
\hline Zaenal D & 0 & 0 & -3 & -4 & -4 \\
\hline Zaenal M & 0 & 0 & -1 & 2 & -4 \\
\hline
\end{tabular}

Nilai-nilai pada baris Pengurang merupakan nilai-nilai yang ditetapkan tim peneliti agar selisih gap di enam baris terakhir pada Tabel 7 masih menghasilkan selisih gap yang masih masuk dalam batasan Selisih Gap yang tertulis pada Tabel 5. 
c. Pembobotan Gap [4]

Data selisih gap pada enam baris terakhir di Tabel 7 kemudian diberi bobot untuk masing-masing kriteria dengan acuan data Bobot Nilai di Tabel 5. Hasil pembobotan gap ini tertulis di Tabel 8.

Tabel 8. Pembobotan Gap di Setiap Kriteria

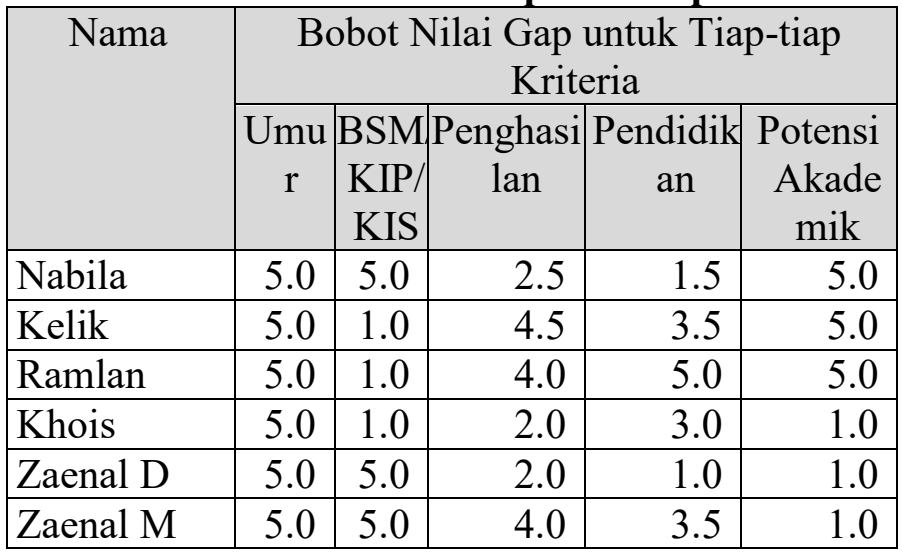

d. Menghitung Core Factor dan Secondary Factor

Kriteria-kriteria pada Tabel 1 dapat dikelompokkan ke dalam core factor (faktor utama) dan kelompok secondary factor (faktor sekunder) [4].

Karena e-book Bidikmisi tidak menulis mengenai kriteria utama dan kriteria sekunder, tim peneliti menetapkan core factor meliputi tiga kriteria yaitu $\mathrm{K} 2$, K3, dan K4; sedangkan secondary factor meliputi dua faktor, yaitu K1 dan K5.

Dari data pada Tabel 8 dapat dihitung nilai core factor dan nilai secondary factor dengan rincian perhitungan ditulis pada Tabel 9.

Tabel 9. Hasil Perhitungan Core Factor dan Secondary Factor

\begin{tabular}{|l|l|c|}
\hline \multirow{2}{*}{ Nama } & \multicolumn{2}{|c|}{ Core Factor dan Secondary Factor } \\
\cline { 2 - 3 } & \multicolumn{1}{|c|}{ Core Factor $(\mathrm{CF})$} & Secondary Factor $(\mathrm{SF})$ \\
\cline { 2 - 3 } & $(5.0+2.5+1.5) / 3=3.0$ & $(5.0+5.0) / 2=5.0$ \\
\hline Nabila & $(1.0+4.5+3.5) / 3=3.0$ & $(5.0+5.0) / 2=5.0$ \\
\hline Kelik & $\begin{array}{l}(1.0+4.0+5.0) / 3 \\
3.333\end{array}$ & $(5.0+5.0) / 2=5.0$ \\
\hline Ramlan & $(1.0+2.0+3.0) / 3=2.0$ & $(5.0+1.0) / 2=3.0$ \\
\hline Khois & $(5.0+2.0+1.0) / 3=2.67$ & $(5.0+1.0) / 2=3.0$ \\
\hline Zaenal D & $\begin{array}{l}(5.0+4.0+3.5) / 3= \\
4.167\end{array}$ \\
\hline Zaenal M & $(5.0+1.0) / 2=3.0$ \\
\hline
\end{tabular}


e. Menghitung Nilai [4]

Core factor meliputi tiga kriteria (K2, K3, K4) maka nilai bobot (lihat Tabel 1) untuk tiga kriteria ini dicari nilai rata-ratanya dengan perincian sebagai berikut:

Rata-rata Bobot K2, K3, K4 $=(30+30+15) / 3$

$$
\begin{aligned}
& =75 / 3 \\
& =25 .
\end{aligned}
$$

Secondary factor meliputi dua kriteria (K1 dan K5) maka nilai bobot (lihat Tabel 1) untuk dua kriteria ini dicari nilai rata-ratanya dengan perincian sebagai berikut:

Rata-rata Bobot $\mathrm{K} 1$ dan $\mathrm{K} 5=(10+15) / 2$

$$
\begin{aligned}
& =25 / 2 \\
& =12.5 .
\end{aligned}
$$

Rata-rata bobot core factor kemudian dikalikan dengan nilai Core Factor (CF) di Tabel 9, dan rata-rata bobot secondary factor dikalikan dengan nilai Secondary Factor (SF) di Tabel 9, dengan perincian ditulis di Tabel 10.

Tabel 10. Menghitung Nilai Akhir

\begin{tabular}{|l|r|r|l|}
\hline Nama & CF & SF & \multicolumn{1}{|c|}{ Nilai } \\
\hline Nabila & 3.0 & 5.0 & $\begin{array}{l}(3.0 * 25)+(5.0 * 12.5)=\mid \\
137.5\end{array}$ \\
\hline Kelik & 3.0 & 5.0 & $\begin{array}{l}(3.0 * 25)+(5.0 * 12.5)=\mid \\
137.5\end{array}$ \\
\hline Ramlan & 3.33 & 5.0 & $\begin{array}{l}(3.333 * 25)+(5.0 * 12.5) \\
=145.83\end{array}$ \\
\hline Khois & 2.0 & 3.0 & $\begin{array}{l}(2.0 * 25)+(3.0 * 12.5)= \\
87.5\end{array}$ \\
\hline $\begin{array}{l}\text { Zaenal } \\
\text { D }\end{array}$ & 2.67 & 3.0 & $\begin{array}{l}(2.67 * 25)+(3.0 * 12.5)= \\
104.167\end{array}$ \\
\hline $\begin{array}{l}\text { Zaenal } \\
\text { M }\end{array}$ & $\begin{array}{r}1.16 \\
7\end{array}$ & 3.0 & $\begin{array}{l}(4.167 * 25)+(3.0 * 12.5) \\
=141.667\end{array}$ \\
\hline
\end{tabular}

\section{f. Perankingan}

Langkah yang terakhir dalam metode Profile Matching yaitu perankingan secara descending atau pengurutan nilai dari nilai tertinggi untuk setiap alternatif [4] (calon penerima beasiswa Bidikmisi), dengan hasil seperti tertulis pada Tabel 11. 
Tabel 11. Hasil Perankingan Nilai Calon Penerima Beasiswa Bidikmisi

\begin{tabular}{|l|l|l|}
\hline \multicolumn{1}{|c|}{ Nama } & \multicolumn{1}{c|}{ Nilai } & Urutan Menerima \\
\hline Ramlan & 145.83 & Urutan 1 \\
\hline Zaenal M & $\begin{array}{l}141.66 \\
7\end{array}$ & Urutan 2 \\
& 137.5 & Urutan 3 \\
\hline Nabila & 137.5 & Urutan 3 \\
\hline Kelik & 104.16 & Urutan 4 \\
\hline Zaenal D & 7 & \\
\hline Khois & 87.5 & Urutan 5 \\
\hline
\end{tabular}

\section{KESIMPULAN DAN SARAN}

\subsection{Kesimpulan}

Kesimpulan yang dapat disampaikan oleh tim peneliti setelah membuat analisis perhitungan pada penelitian ini adalah:

a. Metode Profile Matching tepat dipakai untuk pencarian solusi atas suatu permasalahan jika keluaran akhir dari solusi adalah berupa suatu nilai prioritas.

b. Metode Profile Matching membedakan kriteria-kriteria dari suatu permasalahan dikelompokkan ke dalam core factor dan secondary factor berdasarkan urutan kepentingan dalam penilaian yang berlaku pada metode ini.

c. Secara umum dalam proses pencarian solusi dengan metode Profile Matching terbagi menjadi langkah-langkah penangkapan data dari tiap-tiap alternatif (calon penerima beasiswa), kemudian dilanjutkan dengan perhitungan gap dan pembobotan gap untuk setiap kriteria, perhitungan core factor dan secondary factor untuk tiap-tiap alternatif, perhitungan nilai untuk tiap-tiap alternatif, dan perankingan nilai sebagai solusi akhir. Tahap perankingan nilai merupakan solusi akhir untuk mengetahui urutan tiap-tiap alternatif dalam menerima beasiswa Bidikmisi berdasarkan nilai prioritas yang dimiliki oleh tiap-tiap alternatif.

\subsection{Saran}

Tim peneliti dapat menyampaikan kekurangan dari penelitian ini yaitu belum membahas mengenai implementasi pencarian solusi berupa perhitungan dengan menggunakan paket aplikasi Microsoft Excell ataupun berupa program aplikasi yang ditulis dengan suatu bahasa pemrograman. Untuk itu diharapkan kepada para peneliti lain yang berminat meneruskan penelitian ini di kemudian hari dapat mengimplementasikan pencarian solusi ini berupa implementasi perhitungan dengan 
menggunakan paket aplikasi Microsoft Excell ataupun membuat suatu program aplikasi untuk mencari nilai prioritas tiap-tiap calon penerima beasiswa Bidikmisi. Jika diperlukan maka keluaran akhir dari solusi dapat membedakan calon penerima yang berhak dan tidak berhak mendapatkan beasiswa Bidikmisi yang telah dibahas pada penelitian ini

\section{DAFTAR PUSTAKA}

[1] Prasetyo, E., 2012, Data Mining Konsep dan Aplikasi Menggunakan Matlab, Andi Offset, Yogyakarta.

[2] Ramachandran, P., Girija, N., Bhuvaneswari, T., 2014, Early Detection and Prevention of Cancer using Data mining Techniques, International Jurnal of Computer Applications, No. 13, Vol. 97, 0975-8887.

[3] Kumar, D. S., Sathyadevi, G., Sivanesh, S., 2011, Decision Support System for Medical Diagnosis Using Data Mining, International Jurnal of Computer Science Issue, No. 3, Vol. 8, 1694-0814, :http://www,ijcsi,org/papers/IJCSI8-3-1-147-153.pdf.

[4] Han, J., Kamber, M., Pei, J., 2012, Data Mining Concepts and Techniques, Ed. 3, Morgan Kaufmann, USA.

[5] Djahir, Yulia \& Dewi Pratita. 2014. Bahan Ajar Sistem Informasi Manajemen. Yogyakarta: Deepublish.

[6] Nofriansyah, Dicky. 2014. Konsep Data Mining VS Sistem Pendukung Keputusan. Yogyakarta: Deepublish.

[7] Sianturi, Fricles Ariwisanto. 2015. Implementasi Sistem Pendukung Keputusan Kenaikan Jabatan Guru Dengan Model Profile Matching Pada Sekolah SMA Swasta Raksana Medan. ISSN: 2088-3943. Medan: Jurnal Mantik Penusa Vol. 18, No.2 Desember 2015: 44-52.

[8] S. W. Mudjanarko, S. Winardi, and A. D. Limantara, "Pemanfaatan internet of things (iot) sebagai solusi manejemen transportasi kendaraan sepeda motor," Pros. Semin. Nas. Apl. Teknol. Prasarana Wil. X, no. August, 2017, doi: 10.17605/OSF.IO/6UE4B.

[9] A. D. Triono et al., "Utilization of Pedestrian Movement on the Sidewalk as a Source of Electric Power for Lighting Using Piezoelectric Censors," in 2018 3rd IEEE International Conference on Intelligent Transportation Engineering, ICITE 2018, 2018, doi: 10.1109/ICITE.2018.8492624. 
[10] A. D. Limantara, L. D. Krisnawati, S. Winardi, and S. W. Mudjanarko, "Solusi Pengawasan Kebijakan Mengatasi Kemacetan Jalan dan Parkir Kota Berbasis Internet Cerdas," Semin. Nas. Teknol. dan Rekayasa Inf., no. November, pp. 1-6, 2017.

[11] A. D. Limantara, S. Winarto, and S. W. Mudjanarko, "Sistem Pakar Pemilihan Model Perbaikan Perkerasan Lentur berdasarkan Indeks Kondisi Perkerasan (Pci)," Semin. Nas. dan Teknol. Fak. Tek. Universtas Muhammadiyah Surakarta, no. November, pp. 1-2, 2017, [Online]. Available: https://jurnal.umj.ac.id/index.php/semnastek/article/view/1807.

[12] A. D. Limantara, Y. C. S. Purnomo, and S. W. Mudjanarko, "Pemodelan Sistem Pelacakan LOT Parkir Kosong Berbasis Sensor Ultrasonic Dan Internet Of Things ( IOT ) Pada Lahan Parkir Diluar Jalan," Semin. Nas. Sains dan Teknol., vol. 1, no. 2, pp. 1-10, 2017.

[13] A. D. Limantara et al., "Optimization of standard mix design of porous paving coconut fiber and shell for the parking area," in AIP Conference Proceedings, 2018, vol. 2020, doi: 10.1063/1.5062655.

[14] A. D. Limantara, A. Widodo, S. Winarto, L. D. Krisnawati, and S. W. Mudjanarko, "Optimizing the use of natural gravel Brantas river as normal concrete mixed with quality fc $=19.3 \mathrm{Mpa}$," in IOP Conference Series: Earth and Environmental Science, 2018, vol. 140, no. 1, doi: 10.1088/17551315/140/1/012104.

[15] S. Wiwoho Mudjanarko et al., "The Concrete Quality Testing for Trapezoidal Model of the Prefabricated Foundation," Int. J. Eng. Technol., vol. 7, no. January, pp. 311-315, 2018, doi: 10.14419/ijet.v7i3.25.17588.

[16] D. A. Yulmida, S. W. Mudjanarko, M. I. Setiawan, and A. D. Limantara, "Analisis Kinerja Parkir Sepanjang Jalan Walikota Mustajab," U KaRsT, vol. Volume1, no. nomor1, pp. 39-46, 2017, doi: http://dx.doi.org/10.30737/u\%20karst.v1i1.81.

[17] A. D. Limantara, E. Gardjito, A. Ridwan, E. Sustiyatik, P. Pudijohartomo, and H. L. Sudarmanto, "The Effect of Bioconc Against Compressive Strength of Paving Concrete Combining Natural Materials," vol. 7, no. x, pp. 89-91, 2018.

[18] A. D. Limantara and S. W. Mudjanarko, "Investigasi Forensik Kerusakan Perkerasan Lentur Jalan Raya," UKaRsT, vol. 1, no. 1, pp. 85-105, 2017.

[19] E. Gardjito, A. D. Limantara, B. Subiyanto, and S. W. Mudjanarko, "Role of Project Related Parties on Quality Control (Concrete Structure) and Achievement of Project Performance," U KaRsT, vol. 2, no. 1, pp. 81-100, 2018. 
[20] A. D. Limantara, E. Gardjito, B. Subiyanto, and S. W. Mudjanarko, "Modeling Decision Support to Prioritize Pavement Maintenance Activities in Indonesia," UKaRsT, vol. 2, no. 1, pp. 41-60, 2018.

[21] S. W. Mudjanarko, A. D. Limantara, B. Subiyanto, and F. Nurzandah, "Optimization of Standard Mix Design of Porous Paving Coconut Fiber for Parking Area," UKaRsT, vol. 2, no. 1, pp. 61-80, 2018.

[22] D. A. Restuti, L. Rifani, A. D. Limantara, and B. Subiyanto, "APLIKASI WEB MIX DESAIN BETON BERDASARKAN METODE DOE (SNI 03-28472002)," U KaRsT, vol. 1, no. 2, pp. 36-50, 2017.

[23] E. Gardjito, A. D. Limantara, B. Subiyanto, and S. W. Mudjanarko, "PENGENDALIAN MUTU BETON DENGAN METODE CONTROL CHART (SPC) DAN PROCESS CAPABILITY (SIX-SIGMA) PADA PEKERJAAN KONSTRUKSI,” U KaRsT, vol. 1, no. 2, pp. 80-105, 2017.

[24] N. Damastuti, R. D. Nasihien, A. D. Limantara, and B. Subiyanto, "COMPUTATIONAL FLUID DYNAMICS (CFD) UNTUK SIMULASI ALIRAN FLUIDA PADA BANGUNAN MASJID UNIVERSITAS NAROTAMA," U KaRsT, vol. 1, no. 2, 2017.

[25] A. Situmorang, A. D. Limantara, B. Subiyanto, and S. W. Mudjanarko, "PENINGKATAN DAYA DUKUNG TANAH DASAR LEMPUNG EKSPANSIF DENGAN STABILISASI KAPUR DAN GARAM," $U$ KaRsT, vol. 1, no. 2, pp. 68-79, 2017.

[26] W. Arganata, A. D. Limantara, and Y. Cahyo, “Analisis Perencanaan Overlay Pada Ruas Jalan Craken-Ngulungkulon Nambak-Ngulungkulon Dengan Bahan Acl Menggunakan Metode Bina," J. Manaj. Teknol. Tek. Sipil, vol. 2, no. 1, pp. 121-131, 2017. 